\title{
Study on fracture behaviour of Hybrid Aluminium Composite
}

\author{
Niranjan D. B..$^{*}$, G. S. Shiva Shankar ${ }^{1}$ and Latha B. Shankar ${ }^{2}$ \\ ${ }^{1}$ Department of Mechanical, Siddaganga Institute of Technology, Tumakuru, India \\ ${ }^{2}$ Department of IEM, Siddaganga Institute of Technology, Tumakuru, India
}

\begin{abstract}
This work makes an attempt to study of fracture behaviour of hybrid Composite reinforced with hard ceramic Boron carbide as primary phase and secondary phase as soft solid lubricant Molybdenum Disulphide with base matrix Al2219 by two stage stir casting method is incorporated. Compact tension type specimen was utilized for test and dimensions are conformity to ASTM E-647.Fatigue crack growth and fracture toughness test conducted as per ASTM Standard E-399 and E-1820. This study discloses that reinforcing the hard ceramic Boron Carbide of constant $3 \mathrm{wt} \%$ and soft solid lubricant Molybdenum Disulphide with increasing $\mathrm{wt} \%$ of $3 \%, 4 \%, 5 \%$ to Al2219, results increase in energy required to open the crack front to create two new crack surfaces during mode-I type failure and also significantly variation of fracture toughness. Surface of fractured specimens were study under scanning electron microscope and observes that pulled regions tiny dimples results in balance between ductility and strength of prepared hybrid composite.
\end{abstract}

Keywords: Stir casting, A12219, Fracture Toughness

\section{Introduction}

Aluminium is the most abundantly available material in earth crust. It exhibits numerous properties as conventional alloy however still concern about like strength and stability. In 1990s hard ceramic particles are reinforced with Al, starts new era of aluminium in Metal matrix composites (MMCs), exhibits superior properties like high strength to low weight ratio, resistance to corrosion, thermal stability these properties makes to replace conventional $\mathrm{Al}$ alloy[1-3]. The multifunctional property of aluminium metal matrix has seen utilized major material in space research sector, aerospace technology, substrates of solar panel, electronic heat sinks, antenna reflectors, explosion engine components, fins of drive shaft in automotive and others. Enhancement of material property from aluminium base MMC have been derived to be highly dependent on (i) Composition of base alloy of Al (ii) utilization of weight and volume fraction of reinforcing material (iii) Processing techniques incorporated for fabrication of composites. Thus, most study on composites described in literature has attempted to determine how these causes influences to properties and enhancement of performance of Aluminium Metal matrix composites (AMMCs). Most of study stated in literature has been dedicated to Al composite like A359, 6061, 6063,

\footnotetext{
* Corresponding author: contactniranjandb@gmail.com
} 
7075, A357 [4-6]. Research work on A12219 as hybrid composite is less. However, A12219 made its name in applications like contact parts of airframe and fuel tank of rockets [7-9]. The primary objective of this study is developing hybrid aluminium metal matrix composite using $\mathrm{Al}(2219)$ reinforced with Boron Carbide $\left(\mathrm{B}_{4} \mathrm{C}\right)$ and Molybdenum Disulphide $\left(\mathrm{MoS}_{2}\right)$. The compact tension (CT) specimen were prepared from as-cast and hybrid composite (Al2219) for fracture toughness test of mode-I failure criteria.

\section{Materials and methods}

\subsection{Materials}

For this study Al2219 alloy used as base material as received from in the form of slabs having chemical composition included copper, magnesium as higher percentage and small percentage rare earth material zirconium along with small percentage of vanadium and titanium. Reinforcing particles used are Boron carbide $\left(\mathrm{B}_{4} \mathrm{C}\right)$ of $90 \mu \mathrm{m}$ and Molybdenum Disulphide of $1.8 \mu \mathrm{m}$. $\mathrm{B}_{4} \mathrm{C}$ acting as hard ceramic particle and $\mathrm{MoS}_{2}$ acting as soft solid lubricant. Along with reinforcing particles Potassium titanium fluoride $\left(\mathrm{K}_{2} \mathrm{TiF}_{6}\right)$ halide salt is used for improve of wettability of $\mathrm{Al}-\mathrm{B}_{4} \mathrm{C}-\mathrm{MoS}_{2}$ during melting.

\subsection{Method}

\subsubsection{Stir casting}

The two stage stir casting technique is involved in this study accordance to $\mathrm{K}$ alaneme [1] and Kumar et al [2]. Standardized calculations follows while charging the $\mathrm{Al}(2219)$ billets and reinforcement of $\mathrm{B}_{4} \mathrm{C}$ and $\mathrm{MoS}_{2}$ to produce the combinations of $\mathrm{Al} 2219-3 \% \mathrm{~B}_{4} \mathrm{C}$ $3 \% \mathrm{MoS}_{2}, \mathrm{Al} 2219-3 \% \mathrm{~B}_{4} \mathrm{C}-4 \% \mathrm{MoS}_{2}, \mathrm{Al} 22193 \% \mathrm{~B}_{4} \mathrm{C}-5 \% \mathrm{MoS}_{2} . \mathrm{K}_{2} \mathrm{TiF}_{6}$ was incorporated as wetting agent along with composite to improve wettability of base matrix and reinforcement. For the degassing process Hexachloroethane $\left(\mathrm{C}_{2} \mathrm{Cl}_{6}\right)$ was used. Preheated reinforcements are introduced to process by novel two stage and stir casting process carried to form vortex at speed of 200-250 rpm about 5-8min, for this zirconia coated stainless steel used. Casting was then accomplished on metallic moulds at poring temperature of $720^{\circ} \mathrm{C}$.

\subsubsection{Fracture toughness, $K_{I C}$}

The prepared composites are fabricated to Compact tension specimen as dimensions are conformity to E-647 ASTM standard for the determination of $\mathrm{K}_{\mathrm{IC}}$ of composites. Figure 2.2.2 shows the line diagram of CT specimen. Fatigue crack growth is accordance of E1820 ASTM standard follows the equation (1) for fatigue loading. Notch preparation accordance with E-399 ASTM standard.

where,

$$
\mathrm{P}_{\mathrm{f}}=\frac{0.4 B b_{0}^{2} \sigma_{y}}{\left(2 W+a_{o}\right)}
$$

$$
\begin{aligned}
& \sigma_{\mathrm{y}}=\frac{\sigma_{Y S}+\sigma_{T S}}{2} \\
& \mathrm{~b}_{\mathrm{o}}=\mathrm{W}-\mathrm{a}_{\mathrm{o}}
\end{aligned}
$$

where $a_{o}$ is initial crack length, $W$ is the length from centre of hole grove to initial notch length as shown in line diagram 2, B is thickness of material. $\sigma_{\mathrm{y}}$ and $\mathrm{b}_{\mathrm{o}}$ are obtained as shown in equation (2) and (3). 


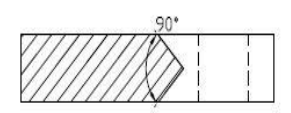

SECTION A-A
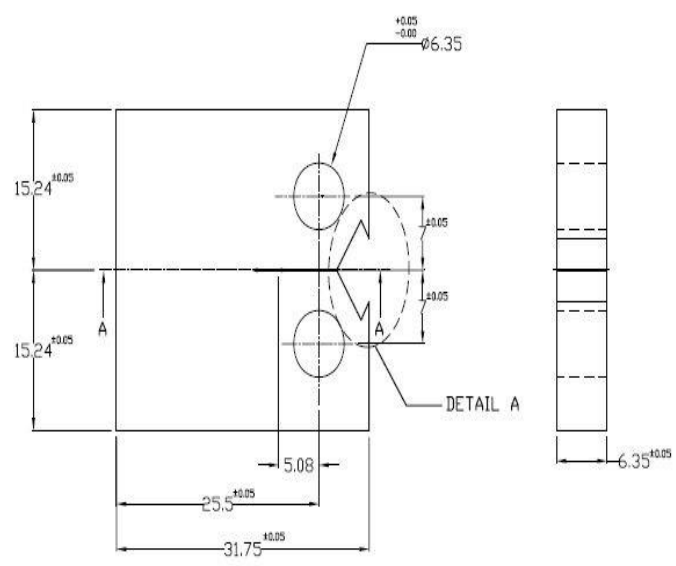

Figure 2: C(T)SPECIMEN FOR 25.4W-6.35 THK

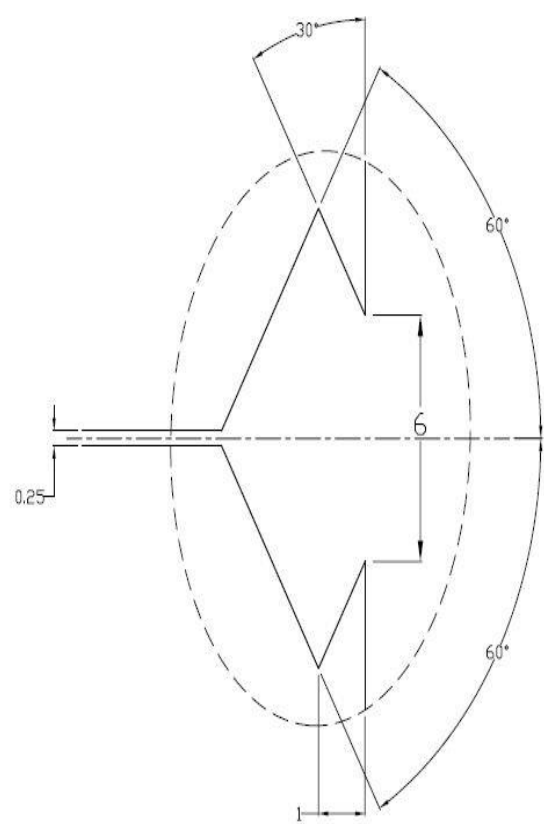

\subsubsection{Microstructure}

The intention of microstructure study is to know distribution of reinforcement particles to base matrix. Initially small diameter of specimen cut down from prepared composites and polished from emery papers, grit size ranging from 200 to 1200 . Characterization of specimen performed by field emission scanning electron microscope.

\section{Results and Discussion}

\subsection{Characterization}
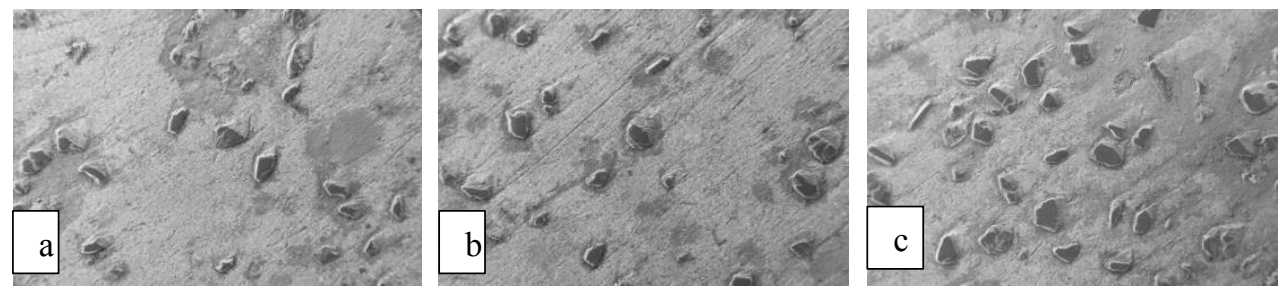

Figure 3.1: FESEM Microimages of (a)Al2219-3\%B ${ }_{4} \mathrm{C}-3 \% \mathrm{MoS}_{2}$, (b) $\mathrm{Al} 2219-3 \% \mathrm{~B}_{4} \mathrm{C}-$ $4 \% \mathrm{MoS}_{2}$, (c) $\mathrm{Al} 2219-3 \% \mathrm{~B}_{4} \mathrm{C}-5 \% \mathrm{MoS}_{2}$

Figure 3.1 shows the particles distribution in the matrix. It clearly observes that from figure 3.1 (a) shows for (a)Al2219-3\% $\mathrm{B}_{4} \mathrm{C}-3 \% \mathrm{MoS}_{2}$, (b) $\mathrm{Al} 2219-3 \% \mathrm{~B}_{4} \mathrm{C}-4 \% \mathrm{MoS}_{2}$, (c) $\mathrm{Al} 2219-$ $3 \% \mathrm{~B}_{4} \mathrm{C}-5 \% \mathrm{MoS}_{2}$, Characterization of specimens are made by field emission scanning electron microscope and this clearly visible of particles of reinforcement $\mathrm{B}_{4} \mathrm{C}$ and $\mathrm{MoS}_{2}$ makes even distribution in $\mathrm{Al}(2219)$ hybrid composite. 


\subsection{Fatigue Crack growth}
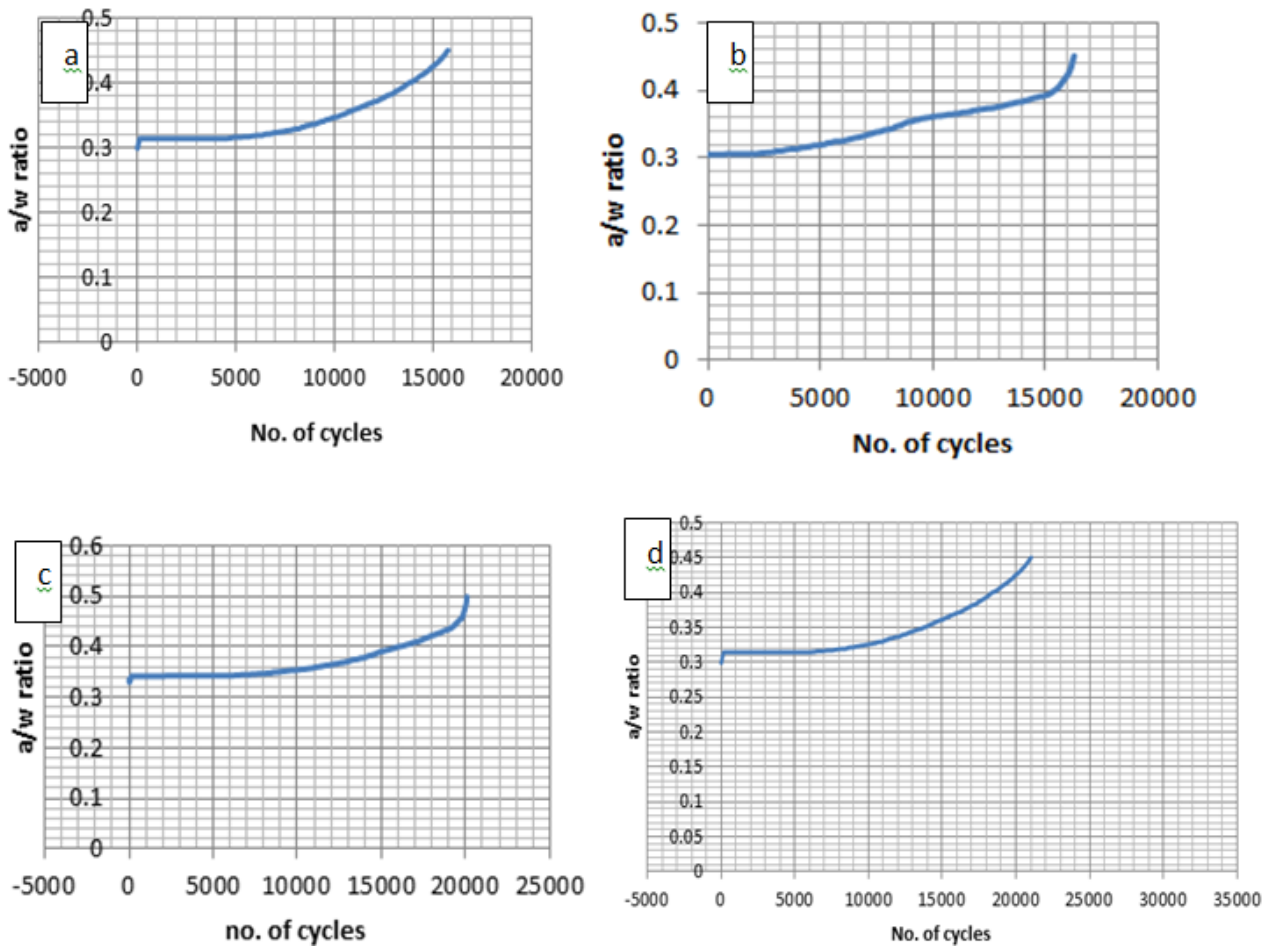

Figure 3.2: graphs of a/w ratio Vs No. of cycles (a) Al2219 (b)Al2219-3\%B 4 C-3\%MoS 2 , (c) Al2219$3 \% \mathrm{~B}_{4} \mathrm{C}-4 \% \mathrm{MoS}_{2}$, (d) Al2219-3\%B $4 \mathrm{C}-5 \% \mathrm{MoS}_{2}$

In this study fatigue crack growth procedure followed by ASTM-E399. Specimen were loaded BiSS axial UTM for tensile loading condition, variable amplitude fatigue crack propagation test was initiated for applying fatigue load. Initially specimens were prepared for $\mathrm{a} / \mathrm{w}$ ratio of 0.3 however by $\mathrm{VAFCP}$ test $\mathrm{a} / \mathrm{w}$ ratio increased to 0.45 and test stops automatically after achieving a/w ratio between 0.45 to 0.55 . For the purpose of obtaining sharp notch at the tip, fatigue load was given. Figure 3.2 shows required number of cycles to achieve sharp notch at tip and standardized a/w ratio.

\subsection{Fracture Toughness}

The significant deviation of fracture toughness is shown in Table 3.3 for as cast and hybrid composite. It observe that addition of hard ceramic $\mathrm{B}_{4} \mathrm{C}$ and soft solid lubricant $\mathrm{MoS}_{2}$ makes increase significantly in the fracture toughness of prepared composites. Reason for improvement is addition of reinforcements makes minimizes in interparticle arrangement and strong obstacle to open the crack front. However only increase in $\mathrm{MoS}_{2}$ makes decrease in fracture toughness as observed in table 3.3. The prepared composites are balance between strength and ductility and $\mathrm{Al} 2219-3 \% \mathrm{~B}_{4} \mathrm{C}-5 \% \mathrm{MoS}_{2}$ combination of hybrid composite exhibits maximum load bearing capacity of $5.565 \mathrm{KN}$ to create new crack surface and also upto $20 \%$ increase in fracture toughness compare to base alloy. 
Table 3.3: Validation $\mathrm{K}_{\mathrm{IC}}$

\begin{tabular}{|c|c|c|c|c|c|}
\hline Composite & Pmax & Pmin & $\mathrm{P}_{\max } / \mathrm{P}_{\mathrm{Q}}$ & $\begin{array}{c}\mathrm{K}_{\mathrm{IC}}(\mathrm{Mpa} \\
\left.\mathrm{m}^{\wedge} 0.5\right)\end{array}$ & $\begin{array}{c}\text { \%increase } \\
\text { in } \mathrm{K}_{\mathrm{IC}}\end{array}$ \\
\hline $\mathrm{Al} 2219$ & 2.052 & 1.959 & 1.047 & 21.485 & - \\
\hline $\begin{array}{c}\mathrm{A} 2219-3 \% \mathrm{~B}_{4} \mathrm{C}- \\
3 \% \mathrm{MoS}_{2}\end{array}$ & 2.147 & 2.054 & 1.045 & 23.002 & $7 \%$ \\
\hline $\begin{array}{c}\mathrm{A} 2219-3 \% \mathrm{~B}_{4} \mathrm{C}- \\
4 \% \mathrm{MoS}_{2}\end{array}$ & 4.236 & 3.863 & 1.091 & 27.326 & $27 \%$ \\
\hline $\begin{array}{c}\mathrm{Al} 2219-3 \% \mathrm{~B}_{4} \mathrm{C}- \\
5 \% \mathrm{MoS}_{2}\end{array}$ & 5.565 & 5.122 & 1.086 & 25.894 & $20 \%$ \\
\hline
\end{tabular}

\subsection{Fractography}
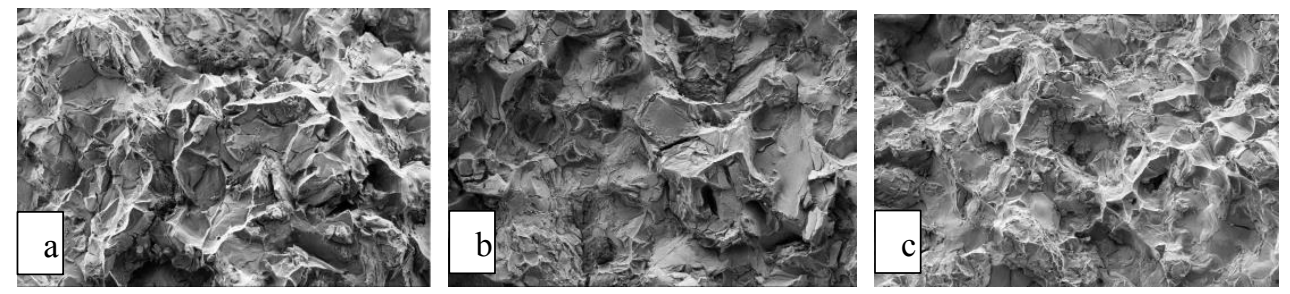

Figure 3.4: SEM microimages of fractured surface: (a)Al2219-3\% $\mathrm{B}_{4} \mathrm{C}-3 \% \mathrm{MoS}_{2}$, (b) $\mathrm{Al} 2219-3 \% \mathrm{~B}_{4} \mathrm{C}-4 \% \mathrm{MoS}_{2}$, (c) $\mathrm{Al} 2219-3 \% \mathrm{~B}_{4} \mathrm{C}-5 \% \mathrm{MoS}_{2}$

Scanning electron microscope is incorporated for study the new crack surface obtained by fracture test. Fig3.4 (a) shows fractured surface of $\mathrm{Al} 2219-3 \% \mathrm{~B}_{4} \mathrm{C}-3 \% \mathrm{MoS}_{2}$ fig 3.4(b) shows fractured surface of $\mathrm{Al} 2219-3 \% \mathrm{~B}_{4} \mathrm{C}-4 \% \mathrm{MoS}_{2}$ Fig3.4(c) shows fractured surface of $\mathrm{Al} 2219-3 \% \mathrm{~B}_{4} \mathrm{C}-5 \% \mathrm{MoS}_{2}$ after conduction of test. Study on surface reveals that the fracture occurred in both intragranular and Trans granular type fracture, combination of cracked particles and pulled regions and tiny plastic dimples, results in mixed mode fracture, which possesses high strength before fracture.

\section{Conclusions}

The present study makes an attempt to study fracture behaviour which involves study of crack tip opening condition and determination of fracture toughness of Al hybrid composite by utilization of Compact Tension specimen with Mode-I failure criteria. Fatigue crack growth and fracture toughness test of as cast alloy and hybrid composite influenced by ASTM E-399 and ASTM E1820 standard.

- It observed that maximum load bearing to open the crack surface of prepared hybrid composite significantly increases. 
- Effect of addition of reinforcement comprise the interparticle arrangement, makes strong obstacle to open the crack front, which results in increase in fracture toughness upto $27 \%$ maximum for $\mathrm{Al} 2219-3 \% \mathrm{~B}_{4} \mathrm{C}-4 \% \mathrm{MoS}_{2}$ hybrid composite.

\section{References}

1. K. K. Alaneme, "Frature toughess and tensile properties of as cast and age hardened aluminium (6063)-silicon carbide particulate composite", Scientia Iranica A (9(4), 992996 (2012).

2. Kumar N. G., "Mechanical and wear behaviour of aluminium metal hybrid composites", Procedia Materials science 5, 908-917 (2014)

3. Jayasheel Harti, "Hardness and Tensile Behavior of A12219-TiC Metal Matrix Composites", Journal of Mechanical Engineering and Automation 2016, 6(5A): 8-12 DOI: 10.5923/c.jmea.201601.02. (2016)

4. Miracle, D. B., "Metal matrix composites-from science to technological significance', Compos. Sci. Technol., 65 (15-16), pp. 2526-2540 (2005).

5. Garcia-Romero A. M., Egizabal P. and Irisarri A. M., "Fracture and fatigue behaviour of aluminium matrix composite automotive piston', Appl.Compos. Mater., 17, pp. 1530 (2010).

6. Adiamak M. "Selected properties of aluminium base composites reinforced with intermetallic particles”, J. Achiev. Matls Manufac. Tech., 14(1-2), pp. $43-47$ (2006).

7. Surappa M. K. "Aluminium matrix composites: challenges and opportunities", Sadhana, 28 (1-2), pp. 319-334 (2003).

8. Soboyejo W. O., "Mechanical Properties of Engineered Materials", Marcel Dekker Inc., New York, USA pp. 1-608 (2003).

9. B. D. Dunn, “The corrosion properties of Spacelab structural alloy aluminium 2219 T851", Published by: ESA Scientific and Technical Publications Branch, ESTEC, Noordwijk (NL) Printed in The Netherlands ISSN 0379 - 4067

10. Nikhil Gupta, "An Experimental and Computational Investigation of Crack Growth Initiation in Compact Tension (CT) Specimen", International Journal of Scientific and Research Publications, Volume 2, Issue 8, August 20121 ISSN 2250-3153 (2012).

11. Y. Lei, "Finite element crack closure analysis of a compact tension specimen", International Journal of Fatigue 30 (2008) 21-31 (2008).

12. Shreyas Pawar, "Experimental Investigation of Mechanical Characterisation of Al6061 Reinforced with Molybdenum Disulphide (MOS2)", Volume 4 Issue IV, April 2016 IC Value: 13.98 ISSN: 2321-9653 International Journal for Research in Applied Science \& Engineering Technology (IJRASET)(2016). 